\title{
Evaluating the Effect of Mozart Music and White Noise on Electroencephalography Pattern toward Visual Memory
}

Syarifah Noor Syakiylla Sayed Daud, Rubita Sudirman*

Faculty of Electrical Engineering, Universiti Teknologi Malaysia, 81310 UTM Johor Bahru, Johor, Malaysia

\begin{tabular}{l} 
A R T I C L E I N F O \\
\hline Article history: \\
Received: 30 May, 2017 \\
Accepted: 18 July, 2017 \\
Online: 05 August, 2017
\end{tabular}

Keywords:

Mozart

White noise

Visual memory

Electroencephalography

\begin{abstract}
A B S T R A C T
Listening to auditory stimuli during study can give positive and negative influence on human cognitive processing. Thus, it has attracted researchers to conduct studies using various types of auditory stimuli. Some researchers believe that Mozart music and white noise are able to give positive influence on cognitive performance. However, most of the past studies gave more attention towards spatial task. Very little studies have been made on the effect of Mozart music and white noise towards memorizing task. Besides, the effect of these auditory stimuli on task difficulty has also not been studied deeply. Hence, the aims of this study were to investigate the effect of Mozart music and white noise on memory performance with different task difficulty levels; and to propose an effective background stimuli condition for memorization. Experiments have been conducted involving 60 healthy adults that required them to memorize the visual memory task with two difficulty levels; i.e. easy and difficult. Brain signal was recorded during memorization duration using 10-20 electrode placement system of electroencephalography (EEG) machine. EEG is a neurological test for measuring and recording the electrical activity of the brain. The effect of sound stimuli on memory performance was evaluated based on memorization test score and brain activity. The wavelet approach was used in processing the EEG data. Based on the memorizing test score result, the subjects are able to memorize better when listening to white noise compared to Mozart music at different difficulty levels. Listening to auditory stimuli can influence the electroencephalography pattern and brain activity. The level of sensory processing and attention increases when listening to white noise which cause the increase of relative gamma (easy level: $p$-value $=0.005$; difficult level: $p$-value $=0.007$ ) and beta power (easy level: $p$-value $=0.001$; difficult level: $p$-value $=0.003$ ). Thus, in this study, it is found that listening to white noise is far more effective in memorizing process compared to Mozart music.
\end{abstract}

\section{Introduction}

This paper is an extension of work originally presented in 2016 IEEE EMBS Conference on Biomedical Engineering and Sciences [1]. Listening to background music/sound during performing cognitive tasks can improve the brain functions, develop creative thinking, make people relaxed, relieve mental stress, and increase work efficiency [2]. Working and studying in silence condition for a long time make people easily to feel sleepy, bored, stress, and lost attention. This condition may affect their performance in solving the tasks. Hence, one of the alternatives to make people enjoyable and effective during doing their activities is by listening

${ }^{*}$ Corresponding Author: Rubita Sudirman, Faculty of Electrical Engineering, Universiti Teknologi Malaysia, 81310 UTM Johor Bahru, Johor, Malaysia Email: rubita@fke.utm.my

www.astesj.com

https://dx.doi.org/10.25046/aj0203173 to auditory stimuli. Auditory stimuli can be defined as events and things that evoke a specific functional reaction in a tissue or organ i.e., the sound that affects our auditory sensations. The auditory stimuli are stimulated when sound cause pressure changes in air or other elastic medium. Usually, the loudness of sound is measured in decibels and travel to the ears as waves. Human ears can detect any sounds within the range of 20 to $20000 \mathrm{~Hz}$. Then, the detected sounds are converted into neural impulses as a result from transduction process. Deafness and hearing loss can occur if the disruptions happen during transduction process. The sounds can be categorized into many types either comes from man-made or natural. The examples of sounds are birdsong, bell sounds, musical sounds, water sounds, and nightlife sounds. Some of the sounds have a beneficial influence on human emotion, psychology, and 
congenital. Thus, many research has been carried out to investigate the effect of sound on human cognition either for children or adult [2-5]. Besides, the development of the biomedical equipment especially the brain modalities i.e. electroencephalography (EEG), magnetic resonance imaging (MRI), computed tomography (CT), magnetoencephalography (MEG), and positron emission tomography (PET) have facilitated the study.

In this globalization era, an education plays the important role for produce a better, independent, successful and knowledgeable people. The knowledge are important and powerful part of human life. Knowledge is an understanding, awareness or information that has been obtained by study or experience by learning, discovering or perceiving, and that is either in a person's mind or possessed by people [6]. Focusing on students life, every day they are learning and expose too much of new knowledge, such as information, facts, descriptions or skills. Examples of student learning activities are memorized the formula, facts, structure of the design, reading, and drawing. All of this requires them to have a better and good memory in order to process the input information. As we know, education system enforced the students to undergo the test, quiz, and examination to identify and evaluate their level of the learning process. The performance of the students in answering the task has depended on their memory ability to interpret the information and knowledge that they have learned and obtained before.

Attention on the student's problem which is some of them is able to recall the required information during the examination, while, some of them are unable to retrieve what they had learned. This situation has relation with their memory capacity to store the information. One of the suspected factors that resulted in this condition is due to wrong chose of study environment. Usually, the students are interested to study in silent or listening to auditory stimuli condition. Thus, this present study aims to help the students by proposing an effective study environment especially for memorizing purpose. The effective study environment is the condition that can give the positive influence on student performance. According to Soderlund et al., 2010 the human cognitive performance can be influenced by the auditory stimuli but depends on the human population, types of auditory stimuli and cognitive task involved [7]. They had done a study to investigate the effect of white noise on inattentive and attentive children when performing episodic verbal free recall test. The test assessment was done in two different conditions: (1) low noise: no noise, and (2) high noise: $78 \mathrm{~dB}$ of white noise. Difference influence has been found between these two children groups which are the performance of inattentive children was improved when listened to white noise but not for attentive children. Based on the Soderlund et al., 2010 [7] findings, we are inspired to discover the effect of environmental factors on memory performance for the normal adult population. Knowing from the previous research that the Mozart music and white noise are able to give the positive influence on people's performance, thus, it's were chosen as auditory stimuli in this present study.
Mozart music is a popular auditory stimulus among the researcher because of its highly structured organization which has potential to excite the same cortical firing patterns that used for cognitive processing [8]. It was considered as a highly structured for three different reasons. First, its harmony has approximately 8bar phrases that separated by definitive cadence points which are easy to distinguish the differences of each section. Besides, the beats were divided equally at a constant tempo. The last reason is it used various types of equipment or voices but often combined into a single. Shaw et al., 1985 reported that the effect of music can be represented by Trion Model [9]. This model suggests that the music has the ability to alter the synaptic weights of neurons in specific patterns due to Hebbian learning principles [8]. In this principle, the brain regions that involve for learning process was explained. They believe that when listening to Mozart music or any music, the neuron firing becomes stronger and each time the new information coming to the memories it's able to process the information actively and decrease the losing of information. White noise can be recognized by 'sh' sound. Some of the researchers reported that listening to it during performing the task able to give a positive influence on cognitive processing [10]. The explanation on how the white noise, improves the cognitive processing represented by the stochastic resonance concept [7]. The simple example to describe this concept is when the weak signal (e.g. visual stimulus) enters the sensory memory it becomes detectable when white noise is added to the signal [7]. The white noise was interacting with the weak stimulus and pushing it or in simple word, it gives motivation to people to give more attention to the required task. Thus, their performance is increase. Stochastic resonance improves the touch, auditory, and visual sensory. The previous works showed that the white noise has improved the human performance in the verbal task, arithmetic task and the spatial task [11-12].

Generally, the human memory can be categorized into three types that are the sensory memory, working memory/short-term memory and long-term memory [13]. The information or stimuli were caught-up by sensory responsiveness and will be stored either in working memory or long-term memory. The human memory easily to be disturbed by external and internal factors such as interference, storage failure, environmental condition, task difficulty, and emotional factors [13-14]. These factors can lead to losing of information. Discovering the effect of sound on memory performance is an interesting work, thus has attracted some researchers to conduct the study $[2,15-16]$. The different style of music/sound gives different influence on memory performance as reported by them. In Boyle and Colheart, and Fu and Kuan, study, the subject required to memorize the task under three different condition; no music, listening to gentle music and heavy music. They had found that the gentle music able to give a positive influence on memory performance compare to the others two conditions. The study by Zhang et al. in 2009 was purposely to investigate the effect of music familiarity on memorizing task under different difficulty level [2]. Their study used visual working memory task with two difficulty level (easy and difficult) with four different types of background condition (no music, Chinese, 


\section{S. S. Daud et al. / Advances in Science, Technology and Engineering Systems Journal Vol. 2, No. 3, 1372-1380 (2017)}

English, and French). The memorizing test score result revealed that the subject had better performance under no noise/silence condition compare to the others. In this present study, the same task assessment as Zhang et al., with some modification was used. A visual memory task that consisted image and number is used in order to avoid the effect of language on subject's performance. The number of items that need to remember is reduce from 15 to 10 items only. The memorizing task was involved in the experiment because it is one of the techniques that used during the learning process. This present study preferred to use Mozart music and white noise as auditory background stimuli because limited of the study had investigate its effect on memory performance.

\section{Review on Past Studies}

This section discuss on the past research that investigate the effect of Mozart music and white noise on human psychology and cognitive performance.

\subsection{Mozart music}

Mozart music was introduced by Wolfgang Amadeus Mozart in 18 centuries. It is classified as a classical music that played using pianos as the major instrument. Although this music was famous long time ago among the musicians and public, it did not attract the researchers until this 20th century. Rausher is the first person who interested to conduct an experiment to investigate the effect of Mozart music on spatial tasks [17]. They reported that listening to Mozart music for 10 minutes had enhanced the spatial reasoning skills. Due to that, many researchers had conducted the study to prove the findings. However, it's become a controversial issue when some of the researchers unable to prove Rausher et al., findings [17-21]. Nevertheless, the others confirmed that there was a significant difference was found in spatial-temporal performance, such as in pencil-and-paper maze tasks and papercutting and folding procedures compare to other environmental condition [22-24]. Up to now, the study on the Mozart effect is still being conducted by researchers as summarized in Table 1. Some of the researchers used the Mozart music as background music for solving or performing certain tasks, whereas some of them used the music alone without any task. Background music can be defined as a condition which the music is played while the listener's primary attention is focused on another task [12] White noise.
Generally, when we talk about the noisy condition, people will imagine the irritating, distracting and uncomfortable sound. The past research has reported that noise attenuates performance on cognitive tasks involving memory, reasoning, vigilance, decision making and vigilance [34-37]. They examine the effect of noise on cognitive performance by using a high volume of noise $(85 \mathrm{~dB}$ and above). According to Broadbent's listening to the high volume (above $90 \mathrm{~dB}$ ) of noise can lead to over-arousal, which causes an increase in stress level [34]. They claimed that listening to highintensity background noise can irritate, disturbs and attenuates vigilance performance [34].

Smith et al., 2003, stated that the effect of noise on cognitive performance is based on three major factors, which is the type of noise, duration, and intensity (loudness) [38]. As an example, when people listening to moderate intensity of white noise $(55 \mathrm{~dB})$ during performing a task, there is only a small effect on performance, however, when the moderate intensity of irrelevant speech is used, it disrupted the person's performance [35-36]. Generally, noise can be divided into several types such as ambient noise, pink noise, and white noise. In this study, the white noise is selected as auditory background stimuli for memorizing the task. White noise can be defined as a sound that is artificially created by combining all audible frequencies in equal amounts [40]. According to new research, listening to the 'sh' sound or white noise consistently could boost the memory [41]. The changes in midbrain activity are examined when the people listening to white noise. This brain part is linked to the learning process and reward pathways. Table 2 shows the past research that uses white noise as stimuli.

The gap of knowledge from previous study and contribution of the present study is focused on three major criteria that are:

\section{(i) Selection of auditory background stimuli}

Most of the study focused on either one of the sounds, whether using the Mozart music or white noise on experiment except study by Bottiroli et al. that has been discussed before [12]. The intensity of white noise selected in previous research mostly around $70 \mathrm{~dB}$ and above. Based on Zhang et al., (2009), they state that the volume greater than $70 \mathrm{~dB}$ will increase the heart rate, blood pressure and cause other responses, thus, it does not suitable to listen for a long duration at this intensity level.

Table 1: Past research of Mozart effect on human

\begin{tabular}{|c|l|l|l|}
\hline Study & Condition and intensity level & Task & Analysis \\
\hline$[25]$ & Silent and listen to Mozart, 60 dB & Visual oddball & EEG signal \\
\hline$[26]$ & Listen to Mozart music and Brahms Hungarian, 60-70 dB & Spatio-temporal rotation task & EEG signal and test scores \\
\hline$[27]$ & Silent and listen to Mozart music (played normally and reversely) & Attentional blink task & Test scores \\
\hline$[28]$ & $\begin{array}{l}\text { Experiment 1: Silent and listening to Mozart } \\
\text { Experiment 2: Silent and Chromatic scales }\end{array}$ & Visual oddball & EEG signal \\
\hline$[29]$ & Silent and listen to Mozart music & Trigonometry tests & Test scores \\
\hline$[30]$ & Mozart music & $\begin{array}{l}\text { Psychological stress test, tinnitus handicap } \\
\text { inventory and visual analog scale }\end{array}$ & Test scores \\
\hline$[31]$ & Listening to Mozart music and Koto music, 55 dB & Science quiz & Test scores and hedonicity of music \\
\hline$[32]$ & Silent and listen to Mozart music, 60-70 dB & - & EEG signal \\
\hline$[32]$ & Listen to Mozart (pre-music, during music, Post-music), 60-70 dB & - & $\begin{array}{l}\text { EEG signal and heart rate } \\
\text { variability }\end{array}$ \\
\hline$[33]$ & Silent, listening to Mozart music and Beethoven music & - & EEG signal \\
\hline
\end{tabular}


S. S. Daud et al. / Advances in Science, Technology and Engineering Systems Journal Vol. 2, No. 3, 1372-1380 (2017)

Table 2: Past research of white noise effect on human

\begin{tabular}{|c|c|c|c|}
\hline Study & Condition and intensity level & Task & Analysis \\
\hline$[42]$ & $\begin{array}{l}\text { Baseline, recorded ICU noise exposure, ICU noise } \\
\text { and mixed-frequency white noise exposure }\end{array}$ & - & $\begin{array}{l}\text { Measures of sleep architecture, total } \\
\text { numbers of arousals, arousal indices, } \\
\text { noise parameters and sleep quality }\end{array}$ \\
\hline$[43]$ & Silent and listen to white noise & $\begin{array}{l}\text { Compound remote associates task, Hopkins verbal } \\
\text { learning test and Rey-Osterrieth complex figure test }\end{array}$ & Test scores \\
\hline$[44]$ & $\begin{array}{l}\text { Listen to white noise, novel sound and high } \\
\text { frequency tone }\end{array}$ & $\begin{array}{l}\text { Pitch difference between the target and standard } \\
\text { stimuli (Easy and hard) }\end{array}$ & EEG signal \\
\hline [45] & Silent and listen to white noise & $\begin{array}{l}\text { Easy task: verbal task } \\
\text { Difficult task: self-performed mini tasks }\end{array}$ & Test scores \\
\hline$[10]$ & $\begin{array}{l}\text { Experiment 1: Silent and listen to white noise } \\
\text { Experiment 2: Silent and listen to white noise at the } \\
\text { left, right and both ear sides }\end{array}$ & $\begin{array}{l}\text { Experiment } 1 \text { : Dichotic listening } \\
\text { Experiment } 2 \text { : Visuospatial working memory task }\end{array}$ & Test scores \\
\hline$[7]$ & Silent and listen to white noise & Episodic verbal free recall test & Test scores \\
\hline [46] & Silent, speech, white noise and Speech + white noise & Visuo-spatial working memory & Test scores \\
\hline$[47]$ & $\begin{array}{l}\text { Silent and Listen to white noise (left side, right side } \\
\text { and both sides) }\end{array}$ & $\begin{array}{l}\text { Verbal memory task and visuospatial working } \\
\text { memory }\end{array}$ & Test scores \\
\hline$[48]$ & $\begin{array}{l}\text { Silent, listen to continuous and short bursts of } \\
\text { white noise }\end{array}$ & Oddball task & Test scores \\
\hline [11] & Listen to white noise & Non-executive and executive function task & Test scores \\
\hline
\end{tabular}

Contribution 1: The effectiveness between of Mozart music and white noise on memory cognitive task are investigated in this study. The sound intensity is control at medium level ( 40 to $55 \mathrm{~dB}$ ) which is safer for longterm exposing to sound especially for study activity.

(ii) Type and difficulty of assessment task

Effect of listening to Mozart music and white noise on task difficulty level (i.e. easy and difficult) does not extremely discover by researchers. Furthermore, the previous research mostly focused on the spatial task ability compares to memorizing process.

Contribution 2: Different difficulty levels (i.e. easy and difficult) of memory task are used in this present study. Thus, the effect of sounds on subject's performance can be investigated either it gives same influence or not for different difficulty level. The memory task is used instead of spatial task because to help the student to find the suitable sound to be listened during memorizing. As we know, memorizing technique is always apply in the study.

\section{(iii) Measurement of memory performance}

The effect of sound on memory performance mostly based on cognitive test score. Less of research focused on the effect of the brain activity. Besides, the relation between the score results and activity of the brain was not further discussed and explored.

Contribution 3: The findings of this study are discussed based on two measurements that are memorizing score result and pattern of EEG signal. The EEG machine was used to record the electrical signal of the brain. The activation of the brain rhythm during task-performing are taken account for explaining on how it gives influence on memory ability to store the input information.

\section{Theoretical}

\subsection{Human Brain}

Brain is one of the largest, unique and complex organ in the human body that located in the head. The shape of the brain is like a walnut and compose of blood vessels, glial cell and millions of the neuron [49]. It is protected by the cranial bones and the cranial meninges. The weight of the adult brain is approximately three pounds or about $2 \%$ of total human's body weight [49]. It is responsible for processing the information, control our behavior, the seat of intelligence and initiator body movement. When receiving input information from the sensory organ, the brain will process the information and then sends the output to muscle. The five sensory responsiveness (touch, smell, visual, auditory, and taste) catch up the stimuli from surrounding and send to the brain to be interpreted before sending to the body for action. The brain can be divided into four main regions that are cerebrum, diencephalon, cerebellum, and brainstem [50]. Each of the regions plays their own roles. The cerebellum can be found behind and below the cerebrum. It is attached to the brain stem. It is responsible for controls motor functions, maintain the body in balance state and interpret the input information from sensory organs [50].

The brain stem is important for basic vital life functions such as controlling and regulation of respiration, cranial nerves, blood pressure, heart rate, breathing, and consciousness in the human body [49]. Besides that, it also functions as a pathway for relaying the information between the brain and the body. It consists of three smaller areas; midbrain, medulla oblongata, and pons. It connects the brain to the spinal cord. Small damage in brain stem areas can cause death. The diencephalon can be found inside the cerebrum. It consists of the thalamus and hypothalamus. It is responsible for maintaining homeostatic balance, sleep cycle, and controlling the motor activities, memories, and arousal. Other than that, it also acts as a relay station for sensory impulses that reach the cerebral cortex, which coming from the brainstem, spinal cord and parts of the cerebral hemisphere. Lastly, the largest region of the brain is 
cerebrum or cerebral hemispheres that make up $85 \%$ of human brain weight [49]. The cerebrum separated into the left and right hemisphere by longitudinal fissure. It can be divided into four lobes that are frontal, parietal, temporal and occipital. Each of the lobes represents their own roles. Table 3 describes the function of each brain lobe.

Table 3: Brain lobe functions [49]

\begin{tabular}{|l|l|}
\hline Region & \multicolumn{1}{|c|}{ Descriptions } \\
\hline Frontal & $\begin{array}{l}\text { Controls voluntary muscular functions, aggression, moods, } \\
\text { motivation and smell reception }\end{array}$ \\
\hline Parietal & $\begin{array}{l}\text { Evaluate sensory information of pain, touch, taste, temperature } \\
\text { and balance }\end{array}$ \\
\hline Temporal & $\begin{array}{l}\text { Center for abstract thoughts and judgment decisions, involve in } \\
\text { memory processes and evaluates hearing input and smell }\end{array}$ \\
\hline Occipital & Receiving and interpreting visual input \\
\hline
\end{tabular}

In this present study, the cerebral region is interested in evaluating the effect of mental task and sound stimuli on it. The study of the brain has started a long time ago among the scientist and philosophers in order to know deeply how does it work, factors affecting and it functions. Due to the lack of advance and modern modalities/equipment had limited the research. In 19 to 20 centuries, the brain imaging modalities are started introducing by scientists. Thus, it attracts many researchers to conduct the study of the brain.

\subsection{Electroencephalography}

Electroencephalography has been introduced by Hans Berger in 1920. The scientist believes that human brain generates electrical signal starting between the 17th and 23rd week of prenatal development and throughout life [51]. When the central nervous system is complete and functional there are approximately $10^{11}$ neurons developing at birth. This assumption has motivated the researchers to apply various type of brain modality in order to know deeply about the brain. Electroencephalography recorded the brain activities by reading the signal that picks up using metal electrode and conductive gel of the scalp. The electrical potential (EEG signal) is generated by the nerve cell of the brain in the cerebral cortex region.

The EEG comes from a combination of three words, which is electro (referring to the registration of brain electrical activity), encephalon (referring to emitting of signals from head) and gram/graphy (referring to writing or drawing) [51]. In research works, the electroencephalography is widely used by researchers compare to other brain modalities due to its ability to record the signal in a short time (milliseconds), low cost, non-invasive technique, not harmless and painful to research subjects.

\section{Experimental}

The experiment has been conducted at the laboratory with controlled temperature, lighting and auditory intensity level. All equipment and materials such as Neurofax 9200 of EEG acquisition machine, ECI electrode-cap, body harness, ear electrodes, ECI electrode-gel, EEG electrode paste, blunted needle, wet tissue, speaker, laptop, pen and answer sheets were prepared and provided before the experiment started. When the subject entered the laboratory room, they were asked to sit on the chair and took a rested for 5 minutes. The instruction and flow of the experiment was displayed on the laptop screen. Then, the subject was required to fill-up the consent form and survey questionnaire. Subject was prepared with all the EEG equipment and material for recording their brain signal. The simulation program was started when the subject ready to take the experiment. Subject need to undergo three different conditions while memorizing the visual working memory task. The subjects were divided equally into two groups to counterbalance the effect of environmental condition on subject performance $[2,12,26]$. Groups 1 were memorized under silence, listened to Mozart music and listened to white noise condition, whereas group 2 undergo silence, listened to white noise and listened to Mozart music condition. The sound intensity level was controlled at 40 to $55 \mathrm{~dB}$ to reduce the effect of loudness on them [52]. Sixty healthy (40 females, 20 males) subjects from Universiti Teknologi Malaysia at the age between 19 to 26 years old with no musical talents were involved in this study. They were selected based on mini-mental state examination (MMSE) to determine their mental conditions. Only subjects that passed the MMSE test were undergo the experiment. The flow of task require to be followed by subjects were as stated below:

\section{Condition 1: Silent}

$>$ Memorize easy level task for 2 minutes and brain signals are record at this time.

$>$ Rest for 30 seconds.

$>$ Recall the task for 2 minutes.

$>$ Rest for 1 minutes.

$>$ Memorize difficult level task for 2 minutes and brain signals are record at this time.

$>$ Rest for 30 seconds.

$>$ Recall the task for 2 minutes.

$>$ Rest while look up the scenery pictures for 3 minutes before proceed to next environmental condition.

\section{Condition 2 and 3: Listen to auditory stimuli}

$>$ Same flows as condition 1 are used for condition 2 and 3 except during the memorizing time the subjects require to listen to the auditory stimuli.

\section{Data Processing and Analysis}

The brain signals were recorded during the memorizing period using EEG machine. The raw EEG signals were saved in ASCII format before processed via Matlab software. Usually, the raw EEG signals were composed of the noise signals that come from the muscle movement (high-frequency noise) and eyes blinking noise (low-frequency noise). Thus, the raw EEG signal needs to be pre-processed for filter the unwanted signal. This present study preferred to use the stationary wavelet transform (SWT) method to remove the high frequency and low frequency of noise. The db3 mother wavelet with 5 decomposition level was chosen to remove the high-frequency noise and low-frequency noise from EEG signals [53-55]. Before filtered the noises, there were 10 out of 20 EEG channels was selected to determine the effect of auditory stimuli on visual memory. The selected channels were frontal: $\mathrm{Fp} 1$, Fz, F8; temporal: T3, T4, T5, T6; parietal: Pz and occipital: O1; $\mathrm{O} 2$. The clean EEG signals were process again using $\mathrm{db} 4$ mother 
wavelet with 7 decomposition level of discrete wavelet transform (DWT) method for obtained alpha, beta, theta, and gamma rhythm. The relative power of each frequency band was calculated.

\section{Result and Discussion}

This part is discuss on the results obtain from the assessment test and EEG pattern. The test scores are determine based on the correct response that answer by the subject. Meanwhile, the EEG features are extract using wavelet transform as mentioned earlier. Statistical analysis of sign test and paired samples $t$-test are used to determine the significant difference between control condition and test condition. The results has been tabulated and graphed in the following section.

\subsection{Assessment test score}

The answered from assessment test were only considered as correct when the filled numbers on figure was same as those were presented. The sign test with 0.05 of alpha $(\alpha)$ level was used to compare the median differences of correct responded between auditory stimuli condition relative to control condition. Two hypothesis has been set as below:

Null hypothesis, $\mathrm{H}_{0}: p$-value $>\alpha$; the median value of test score does not shows a significant different between the test condition and control condition.

Alternative hypothesis, $\mathrm{H}_{1}: p$-value $<\alpha$; the median value of test score shows a significant different between the test condition and control condition.

According to Table 4 and Figure 1, the subjects were able to memorize better when the white noise played for easy (mean: 8.561) and difficult (mean: 4.228) level of the task. A significant difference have been found for median test score of white noise ( $p$-value: easy level $=0.009$; difficult level $=0.01$ ) relative to control condition. Although listening to Mozart music also can improve subject visual memory but it does not give bigger influence on their test score when comparing with the control condition, since no significant difference ( $\mathrm{p}$-value: easy level = 0.203; difficult level $=0.061$ ) was found from the sign-test analysis. Looking at these three conditions it revealed that the subjects' memory ability was improved when listening to auditory stimuli compared to silence condition. This happened because of the positive effect of auditory stimuli on subject's mood, arousal, attention and alertness level, and sensory input processing. Bottiroli et al., 2014, has reported that listening to white noise and Mozart music during performing the mental task will affect the arousal (degree of physiological activation), mood (long lasting emotions), and listener's enjoyment which in turn influence the memory performance [12].

Table 4: Mean and $p$-value of test score result

\begin{tabular}{|l|c|c|c|c|}
\cline { 2 - 5 } \multicolumn{1}{c|}{} & \multicolumn{2}{c|}{ Easy Level } & \multicolumn{2}{c|}{ Difficult Level } \\
\hline Condition & Mean & $\boldsymbol{p}$-value & Mean & $\boldsymbol{p}$-value \\
\hline Control & 7.281 & & 2.912 & \\
\hline White Noise & 8.561 & $0.009 *$ & 4.228 & $0.010^{*}$ \\
\hline Mozart Music & 8.070 & 0.203 & 3.632 & 0.061 \\
\hline
\end{tabular}

Considering the effect of task difficulty level on subjects performance, it showed that the increasing of items need to be remember had degraded the ability to memorize. The easy level of visual memory task gave better result compared to difficult task. Subjects were able to memorize better in easy level compared to the difficult level due to the number of items that need to be remembered were different for each level. In easy levels, the subjects were required to remember 2 digits number with pictures only, but for difficult task, they need to memorize the pictures with 4 digits number. In the control condition, the percentage decreased of test score for easy level relative to difficult level was about $60 \%$. Meanwhile, $50.6 \%$ and $54.6 \%$ were found for white noise and Mozart music. The higher percentage decreased was showed by control condition compared to auditory stimuli condition. From here, it indicated that the auditory stimuli were also improved the memory performance when the difficulty level was increased, especially the white noise.

\subsection{Electroencephalography pattern}

The frequency domain features were extracted from the EEG signal to determine its characteristics when induced by auditory stimuli during memorizing test. The paired samples $t$-test analysis with $\alpha=0.05$ was used to identify the significant different of the relative rhythm power of auditory stimuli condition relative to control condition. Besides, the increasing and decreasing trend of the relative rhythm power of auditory stimuli condition toward control condition also discussed. The hypothesis of paired samples $t$-test is set as below:

Null hypothesis, $\mathrm{H}_{0}: p$-value $>\alpha$; the mean value of relative rhythm power does not shows a significant different between the test condition and control condition.

Alternative hypothesis, $\mathrm{H}_{1}: p$-value $<\alpha$; the mean value of relative rhythm power shows a significant different between the test condition and control condition.

\section{Relative gamma power}

Gamma rhythm $(<30 \mathrm{~Hz})$ is associated with the movement, sensory processing or solving high mental task [51]. In this case study, we are focused on the role of gamma rhythm in activating sensory processing in order to fulfill the study objectives. Sensory processing is an ability of the brain to receive and response to the coming information from sense organ. The sense organs are connected to the human brain via the peripheral nervous system which allowing us to process the input information. Generally, human have five dominant sense organs which are eyes, ears, nose, tongue and skin that use for see, hear, smell, taste and touch. This sense organs contain receptor that transport the input information through the sensory neurons to the nervous system. The ability of the brain in processing the input information can be observed through the relative gamma power value.

Based on Table 5 and Table 6, the white noise (easy level: 67.522 and 65.925) had the highest relative gamma power with significance difference of easy level: $p$-value $=0.005$; and difficult level: $p$-value $=0.007$ ) compared to Mozart music and control condition. However, the Mozart music also showed 
significant difference on relative gamma power for difficult task ( $p$-value: 0.003 ). The relative gamma power was increased for auditory stimuli condition because of the brain need to process information that caught up by the eyes and ears. When listening to Mozart music and white noise, the brain is not only process the upcoming information from the visual but also the auditory stimuli. Different from control condition which is no sound is provided, thus the brain only need to process the information from the visual only. That is the reason why the control condition had lower relative gamma power compared to auditory stimuli conditions.

Next, comparing on difficulty level, it showed that the relative gamma power of control and white noise condition was decreased for difficult task relative to control condition. Meanwhile, the Mozart music showed the highest relative gamma power for a difficult task (64.282) compared to easy task (63.628). So, it indicated that the increases of task difficulty level for Mozart music condition will increase the sensory processing. But, for control and white noise condition, the sensory processing was decreased when the task difficulty level increased.

\section{Relative beta power}

Beta rhythm $(13-30 \mathrm{~Hz})$ is associated with the attention/concentration level, active thinking, focus on the outside world or solving concrete problems [51]. This study focused on the relative beta power for determining the attention/concentration and active thinking level of subjects during memorizing. Based on Table 5, it shows that the relative beta power was the highest in white noise condition for easy (117.318) and difficult (121.218) level of the task. It means that the subjects attention/concentration and active thinking level were significant improved when listening to the white noise during remembering the items as indicated in Table 6 by paired samples $t$-test analysis relative to control condition (easy level: $p$-value $=$ 0.001 ; difficult level: $p$-value $=0.003$ ). However, the attention/concentration and thinking level was significantly improve for the easy level $(p$-value $=0.004)$ but not for the difficult task $(p$-value $=0.141)$ when listening to Mozart music relative to control condition. Among these conditions, the findings showed that listening to Mozart music and white noise able to increase the attention/concentration and thinking level compared to silence condition.

The higher and good attention/concentration level plays an important role when working memory task was involved [56]. In this case study, the subject was only given 2 minutes to memorize all the items, so they need to give full attention on the task in order to memorize it. If they unable to focus on the task during the memorizing time, they will have problem to retrieve back the information later. That is why it is really important to have high beta rhythm during the memorizing process for getting a good test score result. As seen from the result that listening to auditory stimuli makes the subject more attentive and concentrate on the task compared to the silent condition.

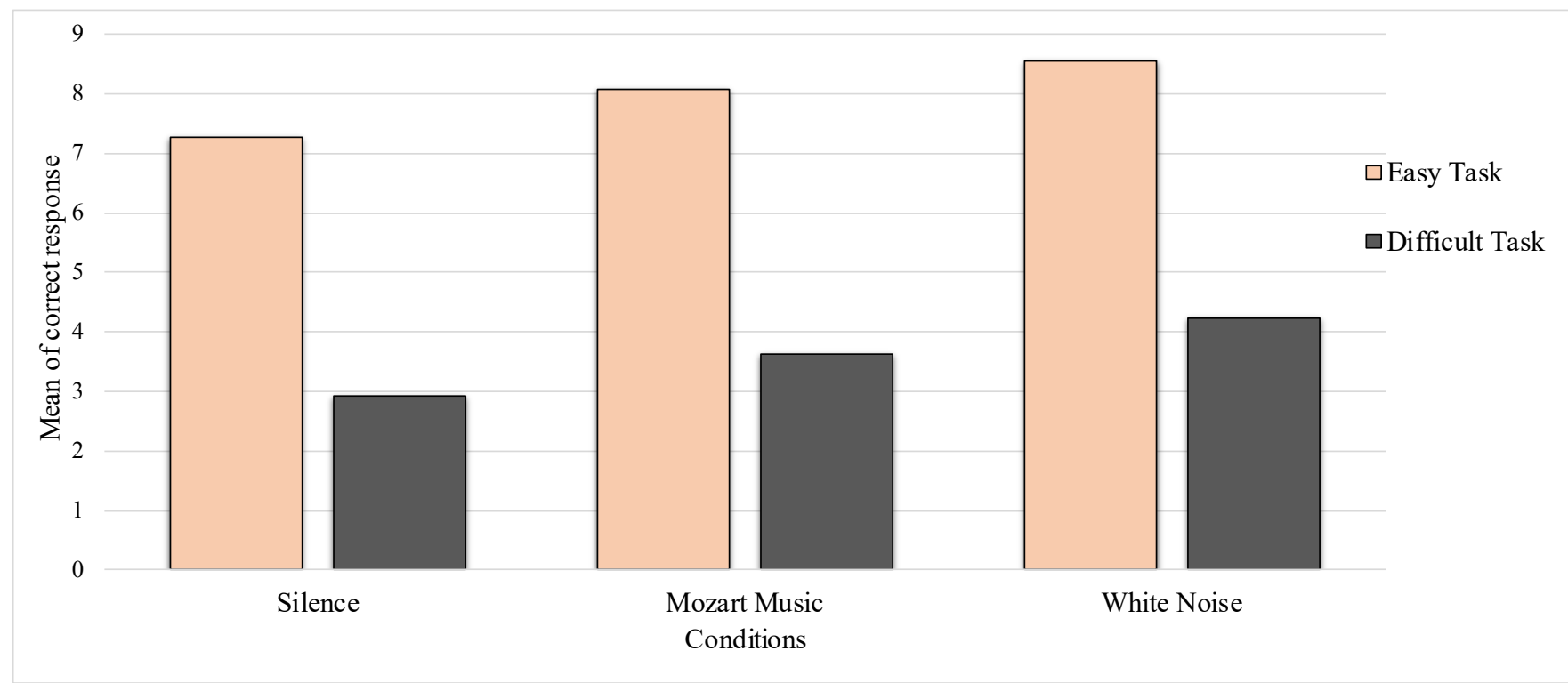

Figure 1: Graph of mean test score at silence, Mozart music and white noise condition

Table 5: Relative power of rhythms for easy and difficult task at silence, listen to Mozart music and white noise condition

\begin{tabular}{|c|c|c|c|c|c|c|}
\cline { 2 - 7 } \multicolumn{1}{c|}{} & \multicolumn{3}{c|}{ Easy Level } & \multicolumn{3}{c|}{ Difficult Level } \\
\cline { 2 - 7 } \multicolumn{1}{c|}{} & Silence & Mozart music & White noise & Silence & Mozart music & White noise \\
\hline Gamma & 60.449 & 63.628 & 67.522 & 59.193 & 64.282 & 65.925 \\
\hline Beta & 111.032 & 115.640 & 117.318 & 113.166 & 115.842 & 121.218 \\
\hline Alpha & 165.469 & 167.464 & 166.372 & 168.520 & 169.526 & 165.092 \\
\hline Theta & 225.215 & 222.400 & 224.511 & 227.440 & 224.280 & 226.487 \\
\hline
\end{tabular}


S. S. Daud et al. / Advances in Science, Technology and Engineering Systems Journal Vol. 2, No. 3, 1372-1380 (2017)

Table 6: The $p$-value of paired sample t-test analysis for relative rhythm power of auditory stimuli condition relative to control condition

\begin{tabular}{|l|c|c|c|c|}
\cline { 2 - 5 } \multicolumn{1}{c|}{} & \multicolumn{2}{c|}{ Easy level } & \multicolumn{2}{c|}{ Difficult level } \\
\cline { 2 - 5 } \multicolumn{1}{c|}{} & Mozart music & White noise & Mozart music & White noise \\
\hline Gamma & 0.124 & $0.005^{*}$ & $0.014^{*}$ & $0.007^{*}$ \\
\hline Beta & $0.004^{*}$ & $0.001^{*}$ & 0.141 & $0.003^{*}$ \\
\hline Alpha & 0.257 & 0.607 & 0.597 & 0.068 \\
\hline Theta & 0.385 & 0.820 & 0.371 & 0.738 \\
\hline
\end{tabular}

The relative beta power was higher for difficult task compared to easy task for all conditions. The reason was due to subject require giving more attention/concentration level during memorizing the difficult task which will increase the relative beta power. It can be concluded that the more items need to remember, the more attention/concentration level was required.

\section{Relative alpha and theta power}

Alpha and theta rhythm associated with the human emotion, mood and arousal state [51]. The frequency of 8-13 Hz (alpha rhythm) represents the relaxed awareness without attention and concentration level. Meanwhile the frequency of $13-30 \mathrm{~Hz}$ (beta rhythm) represents the deep meditation, access to unconscious material, and creative inspiration. According to the paired samples $t$-test result in Table 6, there was no significant difference found for relative alpha and theta conditions of auditory stimuli condition relative to control condition. It showed that no significant influence was found on alpha and theta rhythm when listening to white noise and Mozart music. However, the relative alpha power was the highest when in Mozart music condition for easy level (167.464) and difficult level (169.526) of task compared to others (see Table 5). Listening to Mozart music gave a little influence on subject relaxation state but does not give bigger impact on them since the relative alpha rhythm does not have much difference relative to control condition. The relative theta power showed highest value for control condition for all levels. It means that a little influence was found on theta rhythm roles but not too much when compared to auditory stimuli conditions. From the findings, it revealed that listening to the white noise and Mozart music during memorizing does not makes the subject to feel stress and distract.

\section{Conclusion}

The Mozart music and white noise has different influence on memory performance due to the different types of harmony and beats of the auditory stimuli. White noise has approximately constant harmony and beat, whereas Mozart music has slow, fast, low and high of harmony and beat. Listening to the auditory background stimuli during memorizing the task is able to increase the attention, concentration and thinking level due to the activation of the brain neuron when exposed to it. Before selecting the auditory stimuli to be listened during the learning process, the volume intensity level, type of auditory stimuli, duration, and type of cognitive task should be considered to get positive influence on memory performance. Therefore, in conclusion, this study suggested that the student should listen to white noise at a moderate intensity ( 40 to $55 \mathrm{~dB}$ ) of volume during the memorizing time. The limitation of the previous study has been overcome in this present works in terms of types of task and selection of sound. It has been found that the white noise is more effective to be listened, compared to Mozart music for memory and recall ability of visual task. Therefore, the findings in this study same as the expected outcome and set in the objectives of the study.

a) The auditory background stimuli and task difficulty give different influence on the ability of subject in memorizing the visual task and electroencephalography pattern.

b) The increases of relative gamma and relative beta power has increase the level of attention, thinking, and sensory processing. No significant influence was found for relative alpha and theta rhythm for auditory stimuli condition relative to control condition.

c) White noise is effective to listen during memorizing visual working memory task due to it able to improve the memory performance.

\section{Conflict of Interest}

The authors declare no conflict of interest.

\section{Acknowledgment}

The authors would like to express their appreciation to University Teknologi Malaysia for providing the facilities and funding for this study under vot Q.J130000.2523.13H25.

\section{References}

[1] S. S. Daud, R. Sudirman, "Discovering Sound Effect on Visual Memory Performance based on Electroencephalography" in IEEE EMBS Conference on Biomedical Engineering and Sciences, Kuala Lumpur Malaysia, 2016.

[2] X. Zhang, L. Chuchu, Z. Jing, M. Xiyu, "A Study of Different Background Language Songs on Memory Task Performance" in IEEE International Symposium on Intelligent Ubiquitous Computing and Education, Chengdu China, 2009.

[3] S. Nishifuji, M. Sato, D. Maino, S. Tanaka, S, "Effect of Acoustic Stimuli and Mental Task on Alpha, Beta and Gamma Rhythms in Brain Wave" in IEEE SICE Annual Conference, Taipei Taiwan, 2010.

[4] T. Tamesue, H. Kamijo, H. Itoh, I. Kazunori, I, "Quantitative Evaluation using EEG for Influence of Meaningful or Meaningless Noise on Participants During Mental Tasks" in IEEE International Symposium on Advanced Intelligent Systems, Kobe Japan, 2012.

[5] B. Geethanjali, K. Adalarasu, R. Rajsekaran, R, "Impact of Music on Brain Function during Mental Task Using Electroencephalography" World Academy of Science, Engineering and Technology, 66, 883-887, 2012.

[6] B. Russell, Human Knowledge: Its Scope and Value, Routledge, 2013.

[7] G. Soderlund, S. Sikstrom, J. M. Loftesnes, E. J. Sonuga-Barke, "The Effects of Background White Noise on Memory Performance in Inattentive School Children" Behavioral and Brain Functions, 6(55), 1-10, 2010.

[8] J. Konner, "Does Music Predictability Improve Spatial-Temporal Reasoning? Reexamining the Mozart Effect," Bachelor Thesis, University of Colorado Boulder, 2013.

[9] G. L. Shaw, D. J. Silverman, J. C. Pearson, "Model of Cortical Organization Embodying a Basis for a Theory of Information Processing and Memory Recall” Biophysics, 82(8), 2364-2368, 1985.

[10] G. Soderlund, E. Marklund, F. Lacerda, "Auditory White Noise Enhances Cognitive Performance Under Certain Conditions: Examples from VisuoSpatial Working Memory and Dichotic Listening Tasks" in Fonetik Swedish Phonetics Conference, Stockholm University Sweden, 2009.

[11] S. K. Helps, S. Bamford, E. J. Sonuga-Barke, G. B. W. Soderlund, "Different Effects of Adding White Noise on Cognitive Performance of Sub-, Normal and Super-Attentive School Children" PLoS ONE, 9(11), 1-10, 2014.

[12] S. Bottiroli, A. Rosi, R. Russo, T. Vecchi, E. Cavallini, "The Cognitive Effects of Listening to Background Music on Older Adults: Processing Speed Improves with Upbeat Music, While Memory Seems to Benefit from Both Upbeat and Downbeat Music" Frontiers in Aging Neuroscience, 284(6) 1-7, 2014. 
[13] J. Henderson, "Memory and Forgetting" Routledge. 2005.

[14] N. Cowan, "What Are the Differences between Long-Term, Short-Term, and Working Memory?" Progress in Brain Research, 169, 323-338, 2008.

[15] R. Boyle, V. Coltheart, "Effects of Irrelevant Sounds on Phonological Coding in Reading Comprehension and Short-term Memory" The Quarterly Journal of Experimental Psychology, 9, 398-416, 1996.

[16] H. F. Fu, T. M. Kuan, "Under Different Conditions of Learning Memory in the Electroencephalography (EEG) Analysis and Discussion" in IEEE International Conference on Power Electronics and Intelligent Transportation System, Shenzhen China, 352-355, 2009.

[17] F. H. Rausher, G. L. Shaw, "Music and Spatial Task Performance" Nature, 6447(365), 611, 1993.

[18] J. Newman, J. H. Rosenbach, K. L. Burns, H. R. Matocha, E. R. Vogt, “An Experimental Test of "The Mozart Effect": Does Listening to His Music Improve Spatial Ability" Perceptual and Motor Skills, 81, 1379-1387, 1995.

[19] K. M. Steele, T. N. Ball, R, Runk, "Listening to Mozart Does Not Enhance Backwards Digit Span Performance" Perceptual and Motor Skills, 84(3), 1179-1184, 1997.

[20] C. F. Chabris, "Prelude or Requim for the Mozart Effect?" Nature, 400, 826827, 1999.

[21] K. M. Steele, J. D. Brown, J. A. Stoecker, "Failure to Confirm the Rausher and Shaw Description of Recovery of the Mozart Effect" Perceptual and Motor Skills, 88(3), 843-848, 1999.

[22] F. H. Rauscher, G. L. Shaw, K. N. Ky, "Listening to Mozart Enhances SpatialTemporal Reasoning: Towards a Neurophysiological Basis" Neuroscience Letters, 185(1), 44-47, 1995.

[23] B. E. Rideout, C. M. Laubach, "EEG Correlates of Enhanced Spatial Performance Following Exposure to Music" Perceptual and Motor Skills, 82(2), 427-432, 1996.

[24] E. R. Bruce, S, Dougherty, L, Wernert, L. "Effect of Music on Spatial Performance: A Test of Generality" Perceptual and Motor Skills, 86, 512$514,1998$.

[25] N. Jausovec, K. Habe, K. "The Influence of Auditory Background Stimulation (Mozart's Sonata K. 448) on Visual Brain Activity” International Journal of Psychophysiology, 51(3), 261-271, 2004.

[26] N. Jausovec, K. Jausovec, I. Gerlic, "The Influence of Mozart music on Brain Activity in the Process of Learning" Clinical Neurophysiology, 117(12), 2703-2714, 2006.

[27] C. Ho, O. Mason, C. Spence, "An Investigation into the Temporal Dimension of the Mozart Effect: Evidence from the Attentional Blink Task" Acta Psychologica, 125(1), 117-128, 2007.

[28] W. Zhu, L. Zhao, J. Zhang, X. Ding, H. Liu, E. Ni, Y. Ma, C. Zhou, "The Influence of Mozart's Sonata K.448 on Visual Attention: An ERPs Study" Neuroscience Letters, 434(1), 35-40, 2008.

[29] J. M. Taylor, B. J. Rowe, B. J. "The Mozart Effect and the Mathematical Connection" Journal of College Reading and Learning, 42(2), 51-66, 2012.

[30] G. Attanasio, G. Cartocci, E. Covelli, E. Ambrosetti, V. Martinelli, M. Zaccone, M. Cacciafesta, "The Mozart Effect in Patients Suffering from Tinnitus" Acta Oto-Laryngologica, 132(11), 1172-1177, 2012.

[31] L. Perlovsky, A. Cabanac, M. C. Bonniot-Cabanac, M. Cabanac, "Mozart Effect, Cognitive Dissonance, and the Pleasure of Music" Behavioural Brain Research, 244, 9-14, 2013.

[32] L. C. Lin, C. S. Ouyang, C. T. Chiang, R. C. Wu, H. C. Wu, R. C. Yang, "Listening to Mozart K.448 Decreases Electroencephalography Oscillatory Power Associated with an Increase in Sympathetic Tone in Adults: A PostIntervention Study" Journal of The Royal Society of Medicine, 5(10), 1-7, 2014.

[33] W. Verrusio, E, Ettorre, E. Vicenzini, N. Vanacore, M. Cacciafesta, O. Mecarelli, "The Mozart Effect: A Quantitative EEG Study. Consciousness and Cognition, 35, 150-155, 2015.

[34] D. E. Broadbent, E. A. J. Little, "Effects of Noise Reduction in a Work Situation" Occupational Psychology, 34, 133-140, 1960.

[35] A. P. Smith, "A Review of the Effects on Noise on Human Performance" Scandinavian Journal of Psychology, 30(3), 185-206, 1989.

[36] E. Salas, J. E. Driskell, S. Hughes, Stress and Human Performance, Lawrence Erlbaum, 1996.
[37] S. P. Banbury, W. J. Macken, S. Tremblay, D. M. Jones, "Auditory Distraction and Short-Term Memory: Phenomena and Practical Implication" Human Factors, 43(1), 12-29, 2001.

[38] D. G. Smith, J. V. Baranski, M. M. Thompson, S. M. Abel, "The Effects of Background Noise on Cognitive Performance during a 70 Hour Simulation of Conditions Aboard the International Space Station" Noise Health, 6(21), 316, 2003.

[39] D. C. L. Compte, "Extending the Irrelevant Speech beyond Serial Recall" Journal of Experimental Psychology Learning, 20(6), 1396-1408, 1994.

[40] R. Mehta, R. J. Zhu, A. Cheema, "Is Noise Always Bad? Exploring the Effects of Ambient Noise on Creative Cognition" Journal of Consumer Research. 39(4), 784-799, 2012.

[41] H. R. Vanessa, E. M. Bauch, N. Bunzech, "White Noise Improves Learning by Modulating Activity in Dopaminergic Midbrain Regions and Right Superior Temporal Sulcus" Journal of Cognitive Neuroscience, 26(7), 14691480, 2014.

[42] M. L. Stanchina, M. Abu-Hijleh, B. K. Chaudhry, C. C. Carlisle, C. C. R. P. Millman, "The Influence of White Noise on Sleep in Subjects Exposed to ICU Noise" Sleep Medicine, 6(5), 423-428, 2005.

[43] A. Hillier, J. K. Alexander, D. Q. Beversdorf, "The Effect of Auditory Stressors on Cognitive Flexibility" Neurocase: Case Studies in Neuropsychology, Neuropsychiatry, and Behavioural Neurology, 12(4): 228$231,2006$.

[44] L. A. Combs, J. Polich, J. "P3a from Auditory White Noise Stimuli” Clinical Neurophysiology, 117(5), 1106-1112, 2006.

[45] G. Soderlund, S. Sikstrom, A. Smart, A. "Listen to the Noise: Noise is Beneficial for Cognitive Performance in ADHD" Journal of Child Psychology Psychiatry, 48(8), 840-847, 2007.

[46] G. Soderlund, S. Sikstrom, J. M. Loftesnes, E. J. Sonuga-Barke, "The Effects of Background White Noise on Memory Performance in Inattentive School Children" Behavioral and Brain Functions, 6(55), 1-10, 2010.

[47] S. Flodin, E. Hagberg, E. Persson, L. Sandbacka, S. Sikstrom, G. B. W. Soderlund, "Lateralization Effects of Auditory White Noise on Verbal and Visuo-Spatial Memory Performance" in Swedish Phonetics Conference, Gothenburg Swedish, 2012.

[48] E. Schroder, "The Effect of Auditory White Noise on a Three- Stimulus Oddball Task in Attentive and Inattentive Participants" Master Thesis, University of Lund, 2013.

[49] D. Rizzo, Introduction to Anatomy and Physiology, Cengage Learning, 2012.

[50] M. S. Sweeney, Brain: The Complete Mind : How It Develops, How It Works, and How to Keep It Sharp, National Geographic, 2009.

[51] S. S. Chambers, A. Jonathan, EEG Signal Processing, Wiley, 2007.

[52] C. Sun, Y. Bao, J. Xu, D. Kong, H. Zhou, Q. Wang, H. Shang, W. Wang, M. Jin, X. Wang, Y. Duan, "The Effects of Different Types of Music on Electroencephalogram" in IEEE International Conference on Bioinformatics and Biomedicine, Shanghai China, 2013.

[53] S. S. Daud, R. Sudirman, "Butterworth Bandpass and Stationary Wavelet Transform Filter Comparison for Electroencephalography Signal" in IEEE International Conference on Intelligence Systems, Modelling and Simulation, Kuala Lumpur Malaysia, 2015.

[54] S. S. Daud, R. Sudirman, "Decomposition Level Comparison of Stationary Wavelet Transform Filter for Visual Task Electroencephalogram" Jurnal Teknologi, 74, 7-13, 2015.

[55] S. S. Daud, R. Sudirman, "Artifact Removal and Brain Rhythm Decomposition for EEG signal Using Wavelet Approach" Jurnal Teknologi, 78, 135-143, 2016

[56] M. Matsukura, S. J. Luck, S. P. Vecera, "Attention Effects during Visual Short-Term Memory Maintenance: Protection or Prioritization?" Perception and psychophysics, 69(8), 1422-1434, 2007. 